\title{
Challenges of social justice in mathematics classrooms
}

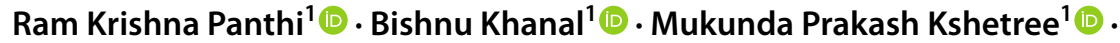 \\ Bed Raj Acharya ${ }^{2}(\mathbb{D})$. Shashidhar Belbase ${ }^{3}\left({ }^{-0}\right.$
}

Received: 14 November 2020 / Accepted: 2 August 2021 / Published online: 1 September 2021

(c) The Author(s), under exclusive licence to Springer Nature Switzerland AG 2021

\begin{abstract}
This study explored the challenges faced by mathematics teachers in promoting social justice in teaching and learning in mathematics in high schools in Nepal. An interpretive qualitative research method was employed for collecting, analyzing, and interpreting data in an iterative process. An in-depth interview method was implemented to collect data from three mathematics teachers on challenges of social justice in mathematics classrooms at three public secondary schools in Kathmandu. A multi-layered thematic analysis and interpretation of the participant narratives from the interview data produced eight emergent themes: diverse students, working-class children, students' absenteeism, disengaging curriculum, students' different interests, non-participatory teaching, insufficient skills in using technology, and cultural differences. Pedagogical and policy implications are additionally considered.
\end{abstract}

Keywords Social justice in mathematics education · Interpretive inquiry · Qualitative research · Diversity · Nepal

Shashidhar Belbase

sbelbase@uaeu.ac.ae

Ram Krishna Panthi

panthirk@yahoo.com

Bishnu Khanal

bkhana11974@gmail.com

Mukunda Prakash Kshetree

mpkshetree@yahoo.com

Bed Raj Acharya

bedraj@tucded.edu.np

1 Department of Mathematics Education, Mahendra Ratna Campus Tahachal, Tribhuvan University, Kathmandu, Nepal

2 Central Department of Education, Tribhuvan University, Kathmandu, Nepal

3 Department of Curriculum and Instruction, College of Education, United Arab Emirates University, Al Ain, Abu Dhabi, UAE 


\section{Introduction}

Nepal has gone through a political transformation from active monarchism to figurative constitutional monarchism and then to the current federal republic system within the last three decades. However, these political transformations could not translate into economic and social transformation significantly. The projected population of the country is about 28 million, which shows an addition of 1 million population since 2010 (World Bank 2021a). The gross national income (GNI) per capita changed from US\$ 540 in 2010 to US\$ 1090 in 2019 (World Bank 2021b). However, this figure may not truly show the economic disparity and uneven distribution of resources, especially at the grassroots level (OXFAM and HAMI 2019). Despite a hope with the rise of literacy rate from $50.6 \%$ in $2003 / 4$ to $65.6 \%$ in $2015 / 16$, still, a large number of primary school children do not complete the first cycle of primary education, and this effect compiles further, and only $1 / 3$ of them reach tenth grade (OXFAM and HAMI 2019). This dismal picture of education attainment has been reflected in several other studies (e.g., Mathema and Bista 2006; Pangeni 2014; Rijal et al. 2018).

The current Constitution of Nepal 2015 mandated the "right of access to basic education" by all citizens and "free education up to the secondary level from the State" (Government of Nepal [GoN] 2015, p. 23). Even the Constitution has mandated the "right to get education in mother tongue" (GoN 2015, p. 23). Accordingly, education policies and acts have been reformulated or revised as per the change in the country's political transformation. For example, the Act Relating to Compulsory and Free Education 2018 has mentioned that every Nepali citizen has the right of access to high-quality education without any discrimination and the federal, state, and local governments have the liability for providing such education free of cost up to secondary level (GoN 2018). With this spirit and imperative to reform school education, the Ministry of Education, Science, and Technology of Nepal introduced the current version of the National Curriculum Framework for School Education 2019 by amending the previous one introduced in 2007 (Curriculum Development Center [CDC] 2007, 2019). The new framework has addressed the issues related to social justice in education in general. For example, it has provided a guideline for reforming curricula of school education based on customs and values, life skills, employment-oriented education, use of ICT in education, education in mother language, child-centered teaching-learning, need-based education and alternative, and open education to provide access to all citizens to high-quality education (CDC 2019). How these policies and guidelines transform into classroom teaching-learning and students' learning outcomes is yet a matter of further study. However, despite these constitutional rights and policies for equity and justice in education in general and mathematics education in particular, the real classroom practices and students' learning experiences have not been changed significantly to impact student achievement and teacher performance in the classroom practices.

Social justice has been a new trend in mathematics education literature. Scholars have suggested ways to promote social justice in the mathematics classroom. 
For example, Brown (2009) suggested developing students' agency and Leonard and Moore (2014) provoked principles to promote social justice pedagogy in mathematics teaching from Cochran-Smith's (2004) social justice pedagogy. These principles are the opportunity to learn, building upon students' knowledge, drawing on students' family history, and making inequity and activism explicit. It has been realized in Nepal that mathematics teaching does not include social and cultural values and it does not promote students' critical and reflective thinking (Panthi et al. 2018b). The general practice of mathematics teaching-learning is direct instruction of banking pedagogy (Freire 1970). It misses the problemposing approach, which can be an alternative to banking pedagogy (Freire 1970).

In this context, it is worth reviewing Gates' (2009) three forms of social justice: a moderate form that focuses on equity and fairness, the liberal form that sees the classroom as a social organ, and the radical form that recognizes structural inequality and seeks to redress the inequality in existing practices. Traditional pedagogy is one of the challenges of social justice in a mathematics classroom in Nepal (Panthi 2017). Working towards social justice seems challenging in the mathematics classroom. These challenges are overcrowded classrooms, different social backgrounds of students and teachers, and lack of resources to use in the classroom (Bista and Mathema 2006). The other issues are related to race, class, and gender due to which students are facing "persistent and profound barriers to educational opportunity" (Darling-Hammond 1995, p. 465).

The additional challenges are associated with students' family, personal interest, diverse contexts, economic status, and social structure as the key factors for social in/justice in mathematics education (Panthi 2019). Educational in/equity is reflected in students' achievement in the standardized tests indicating the achievement gap across gender, race, and socioeconomic status (Esmonde and Caswell 2010). The achievement gap can be one of the reasons for the loss of identity by marginalized students. Therefore, schools and institutions need to work on decreasing the gap by scaffolding marginalized students' learning and uplifting their performance (Gutiérrez 2008). Teachers need to reframe their classroom approach to engage students with meaningful work for learning mathematics. It is the responsibility of all mathematics teachers to address this issue in the classroom (Gutstein 2006) by providing equal priority and opportunity in the classroom and constructing meaning in and through actions (Lindgren and McDaniel 2012). Grant (2020) suggested teachers acknowledge students' experience and prior knowledge from homes and their communities into the classroom and use this mathematical knowledge and experiences in their teaching.

Mathematics education faces unique challenges right from the preservice teacher (PSTs) preparation as unrealistic that does not match instructional experiences (Vomvoridi-Ivanovic and McLeman 2015). Gutierrez (2009) suggests embracing the tension of teaching students and not just teaching of mathematics in the classroom, by developing authentic classroom practices to address the "issues of equity" (p. 14). Despite pedagogical and philosophical aspects of teaching mathematics, there is a challenge in transforming the mathematics curricula and cultures of school to support marginalized students (Martin 2003). The teachers who are willing to promote social justice should create a learning environment to support inquiry-based learning by avoiding inequitable 
power relationships (Garii and Rule 2009). Teachers and schools need to find ways to promote equity within and between diverse groups of gender, socioeconomic status, and ethnicity (Lim and Pateman 2013). A teacher is not expected to have a dominant role and hierarchical power relations with students in a classroom (Bolyan and Woolsey 2016). The classroom practices should be shifted from inequity to equity and inclusiveness by embracing social justice pedagogy (Burton 2003). Mathematics should be accessible to all students (Padilla and Tan 2019) with multiple means of learning and practicing mathematics (Yeh et al. 2020).

Another challenge of social justice has been decontextualized mathematics (Taylor and Luitel 2005). In response to decontextualized mathematics, cultural contextualization of mathematics curriculum may help teachers to make their classrooms socially just and inclusive for all students (Wagley et al. 2008). Without cultural and social contextualization, social justice cannot be achieved through rote learning and the procedural focus of the computational mathematics curriculum (Gutstein and Peterson 2005; Tanko 2014). Therefore, classroom democracy in mathematics education with a pluralistic approach to learning with social justice pedagogy may engage students in contextually rich and meaningful mathematics (Leonard and Moore 2014). These challenges are linked with culturally responsive, social justiceoriented mathematics pedagogies and mathematical modeling practice from dailylife context (Aguirre et al. 2019, p. 7) in an innovative approach in synergistic ways (Aguirre et al. 2019).

Addressing the social justice issues in terms of equity and inclusiveness in mathematics education is a concern (Boylan and Woolsey 2015). Studies in the context of Nepal, for example, view of mathematics as an im/pure subject (Luitel 2013), un/healthy pedagogical practices (Wagley 2016), teacher-centered classroom (Belbase 2006), and need of teaching mathematics for social inclusion and transformation (Pant 2015) advocate socially just mathematics classroom. However, these works are not enough to explore the underlying challenges of social justice in mathematics classroom. Therefore, the purpose of this research was to fill the gap by exploring the challenges of promoting social justice in the mathematics classroom in Nepal. The question addressed in this study was: How do mathematics teachers express their views about the challenges of promoting social justice in mathematics teaching?

In the rest of this paper, first, we reviewed a few pieces literature related to the study. Second, we outlined a theoretical framework of the study. Third, we explained the methodological approach to the study. Fourth, we presented the findings and interpreted them in relation to the theories and other studies. Fifth, we outlined some implications of thematic findings. Finally, we concluded the study with limitations and conclusions.

\section{Literature review}

There are several studies on the issues and challenges faced by mathematics teachers to promote or implement social justice in mathematics classrooms. We presented some studies that focused on the challenges of maintaining equity, access, and 
opportunity to learn mathematics by students of diverse backgrounds, interests, and needs amid differential policy and government emphasis at different places.

\section{Equity}

In its position statement on equity and access, the National Council of Teachers of Mathematics (NCTM 2014) stated that mathematics programs should focus on creating a culture of equity and access for all students despite their backgrounds and knowledge. It emphasized students to have opportunities and access to high-quality learning experience through content, pedagogy, and adequate support to achieve success in mathematical proficiency. The NCTM (2014) suggested stakeholders make sure that all students can access a high-quality curriculum, teaching-learning environment with inclusiveness, and needed support to overcome any challenges in their learning of mathematics.

Skovsmose and Penteado (2011) studied equity and quality issues in mathematics in Brazilian public schools. They applied a qualitative method by interviewing eleven mathematics teachers from different public schools and two prospective mathematics teachers. They used written interviews through email correspondence. The interview questions were related to diversity, equity, and quality issues in public school mathematics. The school scenario of diversity portrays the vivid images of student diversity in terms of places they are from, socioeconomic status, interest, ability in mathematics, personal characters, family situations, creativity, pregnancy and health, drug addiction, and graffiti. When it comes to assessing technology, Skovsmose and Penteado (2011) stated that the number of students with access to the internet and computers increased either at home or cybercafés in their neighborhood. Having access to the internet, computer, and smartphones signified social prestige. However, they also reported many students in public schools came from slums and squatter settlements. These issues further gravitated to personal hygiene and safety due to poverty. The differences among students were not only marked by economic conditions and other social stratifications, but it was also evident from the language and the slang they used. The financial situation and social status reflected health, appearance, and academic roles. Another issue was racism that had deeprooted stigmatization that might have severely affected equity and quality of education with differential learning conditions. From the situational analysis, Skovsmose and Penteado (2011) identified nine important notions as follows: diversity, access, prestige, hope, poverty, learning conditions, possibility, stigmatization, and participation. They suggested educational policy and aim to be aligned towards equity and quality concerning student diversity, access, poverty, stigmatization, and learning conditions.

In another study, Bose and Remillard (2011) analyzed policy reports associated with equity and instructional quality in public school mathematics in the U.S. They analyzed two primary policy documents-Foundations for Success released by the National Mathematics Advisory Panel (NMAP) and No Common Denominator: The Preparation of Elementary Teachers in Mathematics by American Education Schools published by the National Council on Teacher Quality (NCTQ) in 2008. 
Some concerns unveiled in these documents were as follows: a crisis of low achievement, underachievement in mathematics, and weak standing in international comparisons. Bose and Remillard (2011) highlighted these policy documents, including others, to analyze the policy-related challenges to maintain equity, access, and opportunity to education in general and mathematics education in particular. They developed an analytical framework to observe contemporary mathematics education in the U.S. schools from two lenses-student access to mathematical knowledge and the opportunity to participate in meaningful learning of mathematics. Some of the key issues from the analysis were lack of flexibility and connection in mathematics, the limited scope of mathematics in out-of-school context, pedagogical problems, and unskilled graduates of schools. They highlighted equity as an opportunity to learn the mathematics of high cognitive demand beyond routine and trivial computations. These issues advocated reform in mathematics teacher education with a greater emphasis on content coursework. The policy documents emphasized mathematical proficiency through procedural fluency characterizing mathematics knowledge and the process of learning and teaching to be sequential without operationalizing the conceptual understanding (Bose and Remillard 2011). Another major point was related to the privilege of content knowledge over pedagogical knowledge. According to Bose and Remillard (2011), the over-emphasis on content and procedural knowledge might have weakened the pedagogical and curricular knowledge of mathematics teachers leading to the issues of equity and access to high cognitive demand mathematics education.

Aguirre et al. (2017) argued that equity as a basic need to be accomplished as a responsibility of all stakeholders involved in mathematics education. The achievement of equity in mathematics education is possible through a political act of balancing the power relations in the classrooms, institutions, and research processes (Aguirre et al. 2017). Aguirre et al. (2017) suggest four major actions to achieve a greater degree of equity in mathematics education - acknowledging equity as political responsibility in research with a clear focus on equity agenda, advancing knowledge of equity-related works (in curriculum and pedagogy), blending mathematics and equity as one, and expanding the notion of children's funds of knowledge in the mathematics classes.

The National Curriculum Framework for School Education in Nepal, 2007 aimed to "improve access and equity in education, quality and relevancy" (CDC 2007, p. 6). Likewise, the new framework of 2019 has elaborated social justice with guidelines for promoting education as a significant factor for equity and equality in the changed context. This new framework has emphasized the social context with the need and demand of society and pragmatic foundations for the curriculum reform (CDC 2019).

\section{Quality}

Quality of mathematics in the content, pedagogy, and assessment seems critical to achieve equity, access, and empowerment of students. Munter (2014) discussed high-quality instruction in mathematics education in terms of the teacher's role in 
developing a classroom into a community of discourse focusing on mathematical tasks that are problematic and perplexing, promoting connection to prior experiences or context. A mathematics lesson or task with these characteristics may add to social justice with a greater affordance, access, and opportunity to learn high-quality mathematics (Munter 2014). Likewise, high-quality mathematics teaching and learning has been emphasized by NCTM in its standard documents, for example, professional standards for teaching mathematics (NCTM 1991), and principles and standards for school mathematics (NCTM 2000). High-quality teaching and learning mathematics require the teachers to have a high understanding and ability of content knowledge, pedagogical knowledge of planning lessons and activities, engaging students in high-level mathematical tasks with realistic problems of everyday life, and creating opportunities for all students to learn and connect and represent mathematics in a variety of ways (Kentucky Department of Education 2007).

In a recent study, Stoehr (2019) studied preservice teacher reflections across a mathematics teaching module known as the TEACH Math Community Mathematics Exploration (CME) Module. This study engaged 33 preservice teachers on the CME module as a part of their mathematics methods course, intending to provide the opportunity to explore their students, families, and communities to create mathematics lessons to implement in the schools during their student teaching experience. These preservice teachers worked in small groups to develop lessons based on the idea of CME. Then they visited schools and the community where the schools were located to understand some features of the community life. They integrated their module experience and reflection of school and community visits. Iterative analysis of the preservice teacher reflections generated themes. The first theme was opportunities to learn about students and their communities with sub-themes as getting to know students, investment in the local community, embracing the community-mathematics connection and moving beyond the borders of the CME module. The next important theme was about promoting student engagement that included the sub-themes as greater interest in CME, building a classroom community, and feeling of pride (Stoehr 2019).

Nepal's school education has been critiqued for the poor quality of classroom organization, teaching-learning, and teacher performance (Kandel 2018). The poor quality of education has been factored on teacher training (Gautam 2016), underlying traditional philosophical foundation of education (Luitel 2009), convention of paper-pencil assessment (Lamichhane 2018), and decontextualized curriculum and pedagogy (Wagle et al. 2019).

\section{Criticality}

Mathematics education in social justice has been viewed from Freire's (1970) notion of 'critical pedagogy. Mathematics teaching and learning to be socially just, it has to be guided by "critical reading of the word and world through which men and women take themselves in hand and become agents of curiosity, become investigators, become subjects in an ongoing process of the quest for the revelation of the why of things and facts" (Stinson et al. 2012, p. 77). The critical aspect of social 
justice in mathematics education emphasizes the development of students' ability in "dialectical reading of the word and world, so as to rewrite the world.... Learning to perceive social, political, and economic contradictions, and take actions against the oppressive elements of reality" (Freire 1970, p. 35). That means the critical aspect of mathematics education considers students' ability in the reading of the word, and the world plays a significant role in achieving social justice in the classroom through their awareness and mathematical actions to counter the oppressive practices. The critical dimension of socially just mathematics teaching-learning has been well documented in the literature (e.g., Clarkson and Presmeg 2008; Skovsmose 2011; Ernest et al. 2016).

The other features of critical pedagogy focus on pedagogy that develops students' understanding of who they are and how they are related to others through power, culture, and history and challenge the universal foundations and claims of objectivity in mathematics and the process of teaching and learning of mathematics. In this sense, the critical theory of pedagogy also rejects the notion of one-size-fits-all and acknowledges the cultural, historical, and social background of students and teachers to promote dialogical practices (Stinson 2012). Critical mathematics education as part of social justice pedagogy focuses on the situational and contextual approach to teaching and learning by acknowledging the nature of mathematical knowledge as local, contextual, and relational in terms of process and product (Cafezeiro et al. 2017). Cafezeiro et al. (2017) reported that there is a possibility of mathematical knowledge at the local level that fits the local needs of problem-solving.

In a study, Greenstein and Russo (2019) argued that an inquiry-based pedagogy mesmerizes students in their learning experiences with deep thinking, reasoning, pondering upon problems, and reflecting the process of learning by recognizing the prior knowledge of students to promote further learning. Such a pedagogy not only provides content knowledge to the students in a meaningful way, but it also makes students aware of how such knowledge is constructed, transferred, and applied in a variety of contexts to understand and overcome social injustices. Therefore, the critical aspect of mathematics education for social justice emphasizes teaching and learning of mathematics based on the contemporary issues of power relations, equity, access, diversity, identity, and democratic values (Greenstein and Russo 2019).

Morrison (1995) related Habermas's critical perspective of knowledge construction and pedagogical action in school mathematics focusing on the technical, practical, and emancipatory aspects of the curriculum. When there is a bureaucratization in the mathematics curriculum in all forms (intended, enacted, and achieved) that focuses social reproduction rather than reconstruction, there is a limited scope of equity, access, and quality of mathematics that may render the 21 st century skills, attitudes, and dispositions (Bialik and Kabbach 2014; Morrison 1995).

Despite several research studies and theories of critical mathematics education, Nepal still lacks critical perspectives in mathematics teaching and learning and curriculum practices among the teachers and other stakeholders (Belbase 2006; Dahal et al. 2019; Panthi and Belbase 2017). The National Curriculum Framework for School Education 2019 has identified some critical issues and challenges to be considered for reforming school education in Nepal. Among the several points raised, 
some critical challenges related to social justice are the use of assessment as a means of improving teaching-learning, the use of alternative means of student assessment other than tests, translation of teacher training into classroom practice, and multilevel interactions among the stakeholders (CDC 2019).

The review of a few pieces of literature provided a basis to view some challenges of implementing social justice in mathematics classrooms. These challenges not only emanated from the low social and economic conditions and diversity of students' focus, interest, goal, and priority towards mathematics but also systematically originated from some policy documents that emphasized standardization of curriculum, assessment, and classroom practices. These notions helped us to build up a theoretical conception to guide the study process.

\section{Theoretical framework}

The theoretical framework for this study draws upon critical pedagogy, knowledge constitutive interest, and co-creation of the mathematics classroom. Figure 1 depicts the theoretical framework drawing upon Freire (1970), Habermas (1971), and Gutstein (2007) to understand the forces and factors that create challenges in promoting social justice in mathematics classrooms.

The first element of the framework has been drawn upon Paulo Freire's (1970, 1973) notion of critical pedagogy to create a community where individuals strongly change and improve their community. Freire stated that the pedagogy of the oppressed must be "forged with, not for, the oppressed... in the incessant struggle to regain their humanity" (Bartell 2013, pp 130-131). This notion of critical pedagogy challenges social injustice and inequity in the mathematics classroom. Freire's critical literacy integrates political, communal, and fiscal agendas to settle the unjust

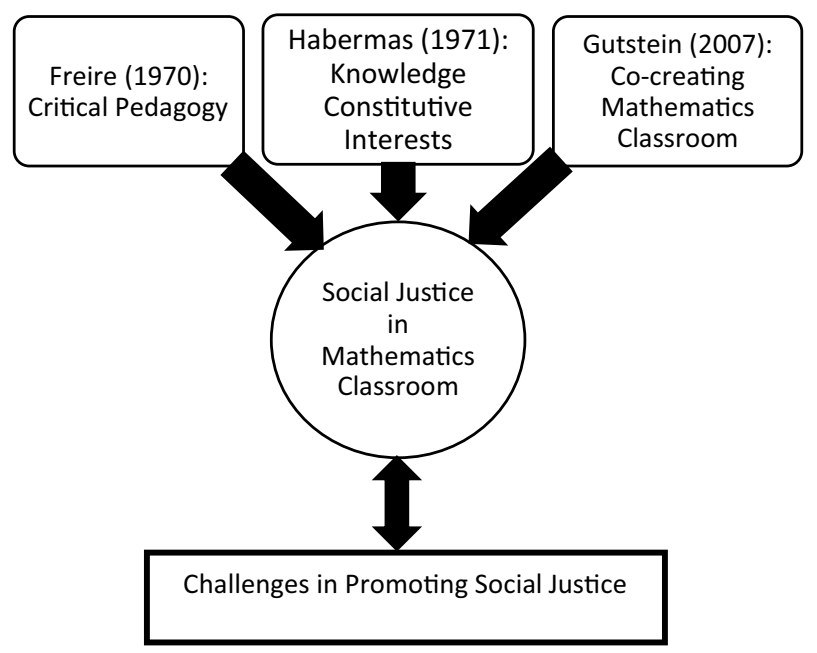

Fig. 1 Theoretical framework of the study 
practices (Stinson et al. 2012). The challenges in promoting social justice in the mathematics classroom can be extended to Yeh et al. (2020) view that "critical pedagogy embraces the struggle against oppression and injustice as a key tenet" (p. 3). Then, such pedagogy can be a lens to question the status quo state and invite critical thinking on role of education and schools as change agents (Motlhaka 2017).

The second element is guided by Habermas's (1971) three knowledge constitutive interests-technical, practical, and emancipatory. Those three interests represent three paradigmatic approaches to knowledge construction in mathematics (and other fields) as empirical-analytic, historical-hermeneutic, and emancipatory. The empirical-analytic science incorporates a technical interest in teaching-learning mathematics that is context-free and objective. The historical-hermeneutic approach to science incorporates practical interest, which considers mathematics teaching to be contextual. The third knowledge constitutive interest aligned with critical science incorporates the emancipatory cognitive interest (Grundy 1987), which is helpful to delve deeper in the existing challenges of social justice in the mathematics classroom.

The third element of the framework is based on Gutstein's (2007) pedagogy of questioning, the political relationship between teacher and students, the dialectical relationship between students to understand power relations and identity development. The questioning pedagogy supports students to raise social issues as a pedagogical context in mathematics. The political relationship between students and teachers is expected to be caring and supportive. The dialectical relationship between students supports creating a community of learners with respect, resilience, and mutual cooperation. Student identity is a complex entity that has to do with classroom, culture, equity, access, and support within and out of school. Then, the teaching of mathematics should not be discriminatory in terms of race, class, gender, language, power, resources, and other variations (Bartell 2013).

We aimed to fit the theoretical framework in the context of this study with critical perspectives on the method and results. Gutstein's theory focuses on reading the word (literacy), reading the world (understand the world), writing the world with mathematics (practical aspect). That means it highlights the real objects, context, literacy, and practical aspect of mathematics in the classroom from the social justice perspective. Habermas's theory guided the study to see which knowledge type and meaning of the mathematical concept and critical thinking have been emphasized in the Nepalese mathematics classrooms. Most of the teachers follow traditional pedagogy with a one-size-fits-all approach, which Freire (1970) is against. The mathematics teachers' views on challenges of implementing social justice in mathematics classes in the Nepalese context have been interpreted in relation to whether the teachers were able to break such a repressive pedagogical approach and what kinds of challenges/issues they were facing in such endeavor. 


\section{Methodology}

A qualitative interpretive inquiry was used as a research approach in this study. The interpretive notion relies on the normative or evaluative facts of input, process, and outcome that best justifies the total set of practices in which that concept is used (Plunket 2013). Interpretive research describes social phenomena to construct knowledge from the interpretation of participants' views and experiences. The methodological approach is qualitative, assuming that social reality is locally and specially constructed in a context (Lincoln and Guba 1985). The hermeneutic process requires the reflexivity of the researchers (Berger 2015). Reflexivity is an active process that influences every stage of the research (Hamdan 2009). Strategies such as repeating interviews with the same participants, member checking, journal writing, and maintaining an 'audit trail' are related to reflexivity within the study (Berger 2015). These processes start from selecting research participants discussed in the next sub-section.

\section{Researchers' position}

The five authors of this paper are mathematics educators teaching both undergraduate and graduate mathematics courses at two different universities, four in Nepal and the other in the United Arab Emirates. All of them had both bachelor's and master's degrees from the same university at different times. They had experience teaching mathematics at middle and high school levels in Nepal before teaching at the university level. They share common cultural and social identities despite differences in geographical locations. However, they endure unique philosophical and ideological standpoints in relation to the social, cultural, and historical context of privilege, power, politics, and identity of individuals and groups in Nepal's context. Their unique beliefs and values from the different philosophical and political standpoints have helped shape the paper through the negotiation of meaning, from both democratic and social, and middle-path aspects, in the context of teaching and learning mathematics in Nepal.

\section{Participants}

The researcher (first author) visited five potential schools to invite research participants for the study. He used three criteria for mathematics teachers from the schools to be included in the study-having teaching experience more than 5 years, being familiar with social justice issues in mathematics teaching-learning with an interest to implement it in their teaching, and interest to volunteer in the study. Out of seven potential high school mathematics teachers from five schools, only three met all three criteria. Therefore, the participants in this study were three secondary-level mathematics teachers (all males) from three public secondary schools in Kathmandu. These teachers were selected for the study based on the convenience in data collection with respect to accessibility, their experience in teaching mathematics, and the ease of conducting interviews with each participant in Kathmandu. The 
three participant teachers were Chandra, Saurya, and Tara (pseudonyms). Participants were from different parts of Nepal and had experiences of teaching mathematics from 5 to 30 years and an age range of 30-56 years. These teachers were selected based on their awareness and interest in implementing social justice pedagogy in mathematics. They tried to promote social justice in mathematics classrooms by asking questions and treating each student equally and equitably. They were accessible to the students in school when they needed any support in learning mathematics besides the regular class time. They claimed to provide extra time (out of the classroom but within school) to promote mathematics learning by marginalized and low achievers. They gave a particular focus on empowering lower achievers during the additional teaching and supporting time. The students were from diverse linguistic, socioeconomic, and multicultural backgrounds in the school. So, they faced several challenges while trying to promote social justice in mathematics classrooms.

Chandra, from a marginalized group, has an M.Ed. and 5 years' experience in teaching, is a high school mathematics teacher at a public school in Kathmandu. Saurya, from a middle-class family, has a B.Ed., and 30 years of teaching experience, is another mathematics teacher at a public high school in Kathmandu. The third participant, Tara, from a middle-class family has an M.Ed. and 26 years' teaching experience, is a mathematics teacher at a public high school in Kathmandu.

\section{Interview protocol}

An interview protocol was designed with five key questions to use as a guide during the interview sessions. The questions were as follows: What are the major challenges in implementing social justice in mathematics class? What are some challenges on the part of the teachers in implementing social justice in mathematics class? What are some challenges on part of the students in implementing social justice in mathematics class? What are some challenges on the part of the school system in implementing social justice in mathematics class? What are other challenges in implementing social justice in mathematics class? These questions were used as ice breakers during the interviews. Follow-up prompts in the second round of interviews were used to get more in-depth opinions of the participants.

\section{Data construction}

The first participant, Saurya, was interviewed two times. The first in-depth interview was administered in his office at school. The second interview took place at his home. Similarly, the second and the third participants, Chandra and Tara, were interviewed twice at their respective schools. Thus, an in-depth interview was conducted with each participant two times. The purpose of the second interview was to consolidate and saturate the codes and themes generated from the first round of interviews for "adequate quality, quantity, and validity" (Read 2018, p. 1). Each of these interviews lasted for about one and a half hours. Mostly, open-ended questions related to challenges of social justice in the mathematics classroom were used during the interviews based on the interview protocol. The interviews focused on 
four key areas: equity in the classroom, access to learning opportunities, treatment to students, and support in their learning of mathematics. While conducting interviews, Freire's notion of critical pedagogy with social and cultural transformation, Habermas's knowledge constitutive interests, and Gutstein's questioning pedagogy were also considered. Each interview was audio recorded. Field notes were maintained during the interviews by noting down the main points to support the analysis and interpretation.

\section{Analysis of interview data}

At first, audio recordings of interviews were transcribed and later translated from Nepali to English for further analysis and interpretation. The transcription notes were read and reread carefully to identify major concepts (open codes) associated with challenges faced by teachers in promoting social justice in the mathematics classroom. The primary open codes were grouped together under common characteristics with a common meaningful unit as major concepts. Major concepts were organized into similar groups under separate themes (axial codes) through categorical analysis of the transcript text and field notes. The concepts were then organized into the final themes (selective codes) by grouping and integrating the concepts as codes (Table 1). Altogether eight themes about the challenges of promoting society emerged from the analysis of data. The five co-authors worked collaboratively to construct the meaning of information found in the classroom context in this study from the interview data during coding and categorizing.

The researchers negotiated the meanings from the codes, categories, and final themes that emerged from the participants' stories with theories and perspectives (Bold 2012). The participants' feelings, emotions, and critical reflections were acknowledged both from the interview transcripts and the field notes. Participant narratives were constructed by integrating their voices expressed during the interviews through the excerpts (Clandinin and Connelly 2000). We examined how the teachers' (participants') perceived challenges were related to and could be interpreted with Freire's notion of critical pedagogy, Habermas's knowledge constitutive interests, and Gutstein's questioning pedagogy.

\section{Ethical issues and quality criteria}

The research process of data collection followed the protocol of informed consent, voluntary participation, right to withdraw, the principle of no harm to participants, and confidentiality of the participants' identity (Christians 2018). The research participants were informed about the study purpose and their rights to voluntarily participate in the study. They were also informed that they could withdraw from the study or not to answer questions if they did not feel comfortable during the interview sessions. Four quality criteria, credibility, transferability, dependability, and conformity, were used to maintain the trustworthiness and authenticity of the data and analysis (Frambach et al. 2013). In order to maintain the credibility of the data, the researcher sent the interview transcripts to research participants to confirm their 


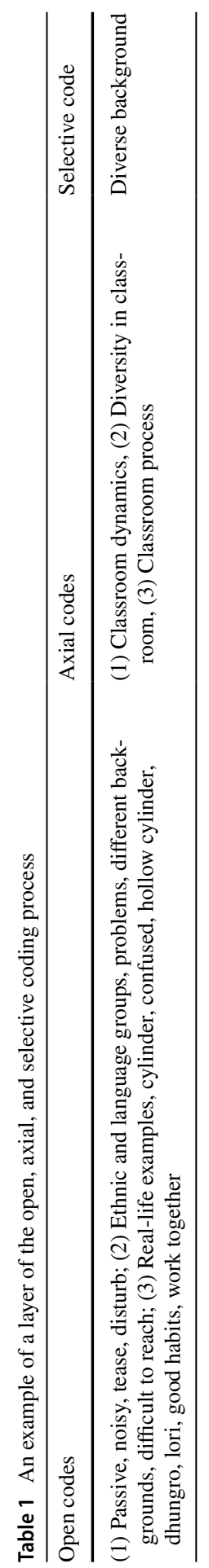


views in which they did not have any objection. The analysis of the data with coding at three levels helped with more robust themes that not only expressed the participants' views on challenges of social justice in mathematics classes, but also, they consolidated the issues as supported by the literature. The process of generating themes with layers of coding processes supported in generating findings consistent with the local context and reduced researcher biases (Frambach et al. 2013; Morse 2018).

\section{Results and discussion}

The results of the analysis of data comprised of eight emergent themes. The themes were as follows: diverse students, working-class children, disengaging curriculum, inadequate prior knowledge, different interests of students, non-participatory teaching, insufficient skills in using technology, and cultural differences. Each of these themes has been discussed in a separate sub-section.

\section{Diverse backgrounds}

Nepal is a multilingual, multi-ethnic, and multicultural nation (Giri 2010). Therefore, mathematics classrooms are also multicultural. Mathematics teachers may need to be aware of multicultural education to accommodate all students' needs in culturally diverse classroom. Nevertheless, it is a challenging issue for teachers to implement social justice. In each class, students come from different backgrounds such as cultural, economic, social, and geographical. Further, they have different native languages. The participants expressed their views about students' backgrounds as one of the key concerns in implementing social justice in mathematics class.

Chandra said, "Some of them (students) are passive and others are noisy too. Some students tease their friends and disturb the whole class" (Interview, August 28, 2016). Similarly, Saurya expressed, "I have students from various ethnic and language groups. Sometimes, I face problems when giving real-life examples. For instance, there is a problem of a cylinder. The students are confused with a hollow cylinder that is used to blow air on fire. The cylinder is locally known as a dhungro, as well as lori. So, when I use a term, some students get confused" (Interview, August 27, 2016). From Tara's voice, "Some of the students who have good habits and work together are good at mathematics. I deal with various students of different backgrounds in the classroom and it is difficult to reach all of them" (Interview, August 29, 2016).

The central concepts from the participant narrative are as follows: students teasing each other, diversity of student background, real-life examples, and student habits. These concepts reflect the classroom dynamics that seemed to pose hurdles or challenges to promote social justice in mathematics classrooms. The students being passive in the classroom or being unruly and creating noise (disturbance to others) and teasing other students can be a symptom of classroom management issues with diverse students. These symptoms also portray that the classroom process is 
not aligned with socially just pedagogy, or the teacher is not balancing between activities, learning process, and reflections. The difficulty in connecting mathematical meaning to real-life contexts, such as dhungro with the concept of a cylinder, demonstrates a challenge in the contextualization of mathematics based on students' background and their prior knowledge. Students being good or not good in mathematics should not be a part of judging students based on their habits, at least from the social justice perspective. In this sense, Tara's claim that different background of students and their habits as posing challenges to implement social justice seems to stem from his biased view about students and their performance.

That means there was a lack of practice of critical pedagogy (Freire 1970) because the classroom practices were not oriented towards engaging students on critical thinking and creating a community of learners for change and improve the conditions of learners. According to NCTM (2000), a mathematics classroom is a place where all students should be stimulated to participate actively, share various ideas, and take part in problem-solving. For this, it may need socially just instruction, which may require teachers to view mathematics education through a social justice perspective. Gutstein and Peterson (2006) noted that "teachers should view students' home cultures and languages as strengths upon which to build, rather than deficits for which to compensate." (p. 3). Verhoeven (2011) highlighted redistribution, recognition, and power as the three factors that affect the outcomes of educational equity. He suggests respecting students' backgrounds and egalitarian views that emphasize equal treatment to all students. However, students in a class are from various backgrounds, such as cultural, economic, social, geographical, and linguistic (Mathema and Bista 2006). Because of this diversity, the same thing may have different meanings for them depending on their home background and the language they speak, bringing challenges for teachers to maintain social justice in the classroom. The diverse background of students also relates to socioeconomic and cultural background that has been the most significant predictor of student achievement in mathematics and other subjects in Nepal (Education Review Office 2018).

\section{Working-class children}

Despite ratification of the United Nations Convention on Rights of the Child (UNCRC 1990) by Nepal on November 14, 1990, and the other provisions to eliminate child labor in Nepal, there is still a significant number of child laborers (International Labor Organization [ILO] Nepal 2020). From the researchers' insider view, a substantial number of working-class children in Kathmandu are in public schools. These children who work for a living seem to be irregular in their mathematics classes. From the participants' viewpoint, it is difficult to make them understand the subject in the classroom due to various reasons.

Chandra said, "I have so many working-class children in my classroom. Many of them are weaker than non-working children. These students do not do homework daily as they are busy with other works at home. They are, therefore, weak at mathematics. Most of those working-class children tell me that they do not have enough time to study and do assignments at home as they have to do a lot of household 
work" (Interview, August 28, 2016). Saurya has a similar problem in his classroom. Many of his students are also working at others' homes. They do not have time to do homework at home. Some of them leave class for their work at home. This scenario shows a challenging situation for these students to continue school. Saurya expressed, "Some guardians even punish students physically and mentally if they do not work at home. So, they do not show any interest in their study" (Interview, August 27, 2016). Tara, too, has a similar problem as there are many working-class children in his mathematics class. Tara lamented, "These students seem tired, and they are busy with household works in the morning and evening (out of school time). They have no time to study and practice mathematics at home. They also have behavior problems in the class. Some students do not change their bad habits and behavior. They do not know how to behave with teachers and other students" (Interview, August 29, 2016).

The main concepts drawn from the narrative of the participants are as follows: students as child laborers, less time for mathematics, weakness in mathematics, physical punishment, behavior problems, and lack of student interest. Especially in the Kathmandu valley of Nepal, most of the middle and high-income families send their children to private schools. Therefore, public schools are the places of education for lower-income and marginal families and working-class children. These children have low motivation to learn any subjects in general and mathematics in particular due to workload at home either as helping hands to parents or domestic helpers at other's houses. As a consequence, these children are weak in mathematics. Even they leave classes early or drop entire courses when they have more work at home. The guardians or parents do not have adequate income to support their children's education and day-to-day survival. Then, they expect their children to work with them. These children seem to be tired or exhausted due to excess workload at home or due to a lack of sleep or other issues. Some of them also seem to have behavior problems due to a lack of discipline at home or lack of respect and responsibility for their parents or guardians. The teachers may not be aware of what is going on with these children and their parents at home. The low socioeconomic status of the children and their parents might be the major root cause of such problems. In such a case, implementing social justice pedagogy in the mathematics classroom is immensely challenging due to a lack of support from the government and local municipalities and lack of parental involvement in their children's education. These sets of issues seem to pose a more significant challenge to maintain a classroom with equal opportunity to learn, have student voice in learning, equal access to all resources, and develop a sense of community of learners.

When school-going children have to earn for their living and supporting family, then there is a slim chance of promoting the emancipatory cognitive interest of learners as envisioned by Habermas (1971). The existing challenge seems to be associated with not only classroom context but also the broader socioeconomic status of students and their families. Research has shown that low-income and working-class students frequently do less well than middle and upper-class students on standardized tests like racial minority students, aboriginal students, students with a learning difficulty, and students who speak English as an additional language (Kelly and Brandes 2008). It is believed that students from working-class families are 
challenges in promoting social justice in the mathematics classroom. Many students in the school were working-class children who had poor knowledge of mathematics. The working-class students frequently did less well than middle and upper-class students. This situation is problematic for promoting social justice in the classroom in Nepal. One of the reasons for not being attentive to the mathematics classroom can be attributed to the conditioning of working-class family tradition (Hodge 2015). These students may be more interested in working at home rather than mathematics or learning mathematics because they gain immediate monetary benefits from their work and stay out of the classroom problems (Mathema and Bista 2006; Quaye 2020). It is difficult for teachers to empower them. It takes time to convince and persuade them. Students are compelled to go for labor work for a living. Teachers have to focus on weak students in the classroom, and they should refer to the administration for providing scholarships to targeted students. It also seems that there are unequal power relations between students and teachers and between good and weak students in the classroom.

\section{Student absenteeism}

It seems that students' absenteeism is another significant problem in mathematics classrooms in public Schools of Kathmandu. Chandra views that students' absenteeism is a challenge in promoting social justice in the classroom. He sometimes teaches essential subject matters of the course for the students who are absent in the class when they do not understand other topics due to the lack of prior knowledge.

Chandra said, "The students afraid of asking questions to their teachers, especially the ones who are weak. This situation is a challenging problem in the classroom. During class time, students go to visit different places outside the school, and some of them do not return school when they bunk their class periods" (Interview, August 28, 2016). Chandra finds it challenging to make students understand different concepts when they missed the classes. On the other hand, Surya has a similar problem. Surya expressed his worries, "Because of their irregularity in the classroom, these students do not understand topics, but I am compelled to move to another topic as I have to complete the course on time. I also take fine from the absent students so that they will be discouraged from being absent in their classroom. I think that the regularity of students is increased day by day because of the fine" (Interview, August 27, 2016). Tara also reported that many of his students are frequently absent in school and avoid class even when they are in school. Tara shared, "As a result of missing classes, students are weak in mathematics, including other subjects. This situation creates inequity in the mathematics classroom in terms of teaching and learning" (Interview, August 29, 2016).

The main concepts from the participant narrative are as follows: lack of questioning behavior, frequent absence in school, economic status, bunking of classes, and compulsion to complete the course on scheduled time. Why would students be afraid of asking questions in the class? This issue seems pervasive in Nepalese mathematics classes demonstrating excessive power and authority to the teacher to control the class at one hand (pedagogically). However, another question can be raised together 
with it: Why would students bunk classes? Although the teachers seem to have the authority or power to control the class (pedagogically), they fail to motivate the students towards the study. Students going out of school during the school time and not returning to the classes seem negligent of school administration and the teachers in keeping the children in the school during school hours. This issue might undoubtedly lead to unsocial activities on the part of children when they go out of the classroom and take part in other activities, such as hazardous works and drug abuse (ILO 2020). These elements seem to affect students' active participation with continuation in the mathematics classroom, thus creating a gap between regular students and partially attending students.

Students being absent in school or classroom might be a challenge to promote social justice in the mathematics classroom, and it portrays a broader picture of lacking policy and implementing such policy even if it exists (e.g., constitutional right of free basic and high school education). In this context, Bhattarai (2017) reported factors such as time for students to study at home, parents' education, and employment (especially mother) had a positive impact on school attendance of high school students in Nepal. Lack of student participation in classroom practice, lack questioning, and reasoning practice can be another reason for student absence in mathematics classes in Nepal. According to Gutstein (2007), implementing questioning pedagogy and developing a supportive and caring environment in the classroom may reduce students' absenteeism. The phenomenon of absenteeism disturbs students' performance, promotion, dignity, and future job possibility (DeKalb 1999). We agree with the participants that student absenteeism is one of the significant challenges in the classroom. It is one of the problems for making equitable classrooms. The irregular students feel difficult to understand topics, and they are weak at mathematics. Therefore, student absenteeism has an adverse effect on maintaining social justice in the classroom. Absenteeism has been considered as a critical factor for low student motivation, poor achievement, and school drop out as a social problem (ChavesBarboza et al. 2019) which has posed a challenge in maintaining social justice in mathematics classroom in Nepal. A prior study conducted in Nepal reported parents voice "Due to household poverty, our children are used in assisting household works or family's income-generating activities which prevent them from being regular in the school and we even cannot compensate the loss of school studies through other means" (Mathema and Bista 2006, p. 86). This is a perpetual problem in public schools in Nepal. Students' absenteeism challenges social justice in the classroom. It is difficult to maintain an equitable mathematics classroom due to student absence in mathematics classrooms. Absenteeism brings inequity in the classroom.

\section{Disengaging curriculum}

It has been realized that engaging students with mathematics problems is a challenging task for many teachers. The curriculum does not emphasize practical aspects of mathematics, and there is no assessment of practical aspects of it.

Chandra expressed, "The interest of students is increased towards mathematics when they are engaged in mathematics learning. The practical application provides 
a strong knowledge of applied mathematics in everyday life. However, our students are weak in solving practical problems. The course contents are not related to daily life, society, and culture. So, it is necessary to relate our course with social, political, and environmental aspects of students' lives" (Interview, August 28, 2016). Surya also said that the curriculum is more theoretical and more content-based. He pointed out that students are not interested in learning theoretical concepts in mathematics. Surya added, "My students occasionally find solutions to some problems but do not solve applied or practical problems in the classroom. I think the assessment system should be reformed in such a way that it guides mathematics teaching and learning. In addition, the mathematics curriculum should be related to the culture and daily lives of students. It should be practical and useful to solve daily life problems" (Interview, August 27, 2016). In a similar vein, Tara said, "The mathematics curriculum focuses more on content but less on creative aspects. Students are not engaged practically in many classes. The curriculum should be reformed by focusing on local context or situation" (Interview, August 29, 2016). He emphasized creativity in mathematics together with computation and calculation of different problems. He gives less value to student experience due to the assessment system. This view means he has a compulsion to complete the course on time. So, it is challenging to engage students in practical tasks. We can see that there is a tension between the classroom context and outside worlds, which is a source of inequity in the classroom.

The key concepts from the above narrative are as follows: students have low motivation, less connection of mathematics to everyday life, rigid assessment system, procedural learning, and decontextualized curriculum, thus disengaging students in learning. The participants' views clearly demonstrate that there is acute challenge in promoting social justice in mathematics classes in public schools in Kathmandu. However, these challenges reflect back to the school system and the teachers themselves more and less on the side of the students. Who is the one that is going to integrate mathematics with daily life? Who is the one who is going to teach mathematics in a culturally relevant way? Why would students be not interested to solve practical or applied problems? Why is the mathematics curriculum less culture friendly and student friendly in Nepal despite students coming from different cultural backgrounds? The views of the participants raise more questions on how they are engaged in promoting social justice in mathematics classes in public schools in Kathmandu. It seems that there is a general lack of intention to implement social justice in mathematics classroom, at least from the institutional efforts and plans. The mathematics curriculum and classroom practices seem not grounded on the students' lives and their needs in general in Nepal. These are some of the practical challenges to promote social justice in the mathematics classroom.

The above-mentioned challenges and issues related to disengaging curriculum and classroom practices align with Habermas's (1971) technical interest with a focus only on the mechanistic process of mathematics teaching and learning. It seems that there is a general lack of Habermas's practical interest to integrate classroom mathematics to students' daily lives. Doerr and Chandler-Olcott (2005) noted that reform-based curricula place new reading and writing demands on both teachers and students. These demands may affect marginalized students unfavorably because of 
their lack of cultural capital. The mathematics teachers may capture different cultural experiences of students, which are related to mathematics to motivate them in learning. It is traditionally believed that mathematics is difficult for weak and marginalized students. It may require practical mathematics in which students learn with action and give reflection. Gebremichael (2014) stated that there is no proper blending between mathematics learning and its application due to students' less inspiration on involving themselves in mathematics and low utilization of mathematics notions. Michelsen and Sriraman (2009) explained that poor application of mathematics notion is due to students' dilemma of translating word problems that are difficult to perceive. Mathematics teaching is characterized by a "fragmented collection of facts, techniques, and theorems that bear little relation to each other... with no connection with real life (Yasoda 2009, p. 7)" is also a persistent challenge for social justice in mathematics classrooms in Nepal. A solution can be proposed for making relations between mathematics and other school subjects through word problems and relevant problems from different contexts (Gebremichael 2014).

It seems that the mathematics curriculum in Nepal does not seem to focus on student engagement in the classroom. It just produces rote learners. However, mathematics is a practical subject in which students' engagement is necessary for the school. The curriculum gives less preference for engaged learning. Therefore, the curriculum needs to be changed based on students' demands, society, and political context to broader inclusiveness and access to high-quality mathematics and its pedagogy.

\section{Different interests of students}

It is generally accepted that students have varied interests in learning mathematics. They have different backgrounds and goals in their lives. They are interested in learning things that are related to their goal. Chandra argued that students have various interests in different subject areas.

Chandra expressed, "Some students are interested in reading stories but less interested in doing mathematics. Their individual differences in home environment and future interest are challenges for socially just teaching in the mathematics classroom" (Interview, August 28, 2016). Saurya also finds that his students have different interests, such as some of them are interested in geometry; others are in algebra, and rests are in arithmetic. Surya opined, "Students have different interests in different subject areas. For instance, some like English, or Nepali or Social subjects, but they do not like mathematics" (Interview, August 27, 2016). Tara also said, "Different interests of students is one of the challenges of social justice in the mathematics classroom. Some students are not interested in mathematics, reading, and writing. They make noise in the classroom. The students who want to do catering (to earn money) and as an assistant in driving (to collect fare), and they do not show any interest in their studies" (Interview, August 29, 2016).

The principal concepts drawn from the participant narratives are as follows: students more interested in reading stories than doing mathematics, a variety of interest to cope in the classroom, and earning during out of class time. As per the views 
from the participants, the students are interested in stories, but not in mathematics. Teachers seem to be aware of the different interests of students. Students' interest and motivation to learn different areas of mathematics seem different, such as algebra, arithmetic, and geometry. Why would they like one area more compared to other areas? Does it have to do something with their learning style or approach to different domains of mathematics? Why would these students like social and language subjects rather than mathematics? Isn't it a part of teachers' responsibility to raise their engagement and interest in learning mathematics? Although the research participants seemed to believe that students' differential interests posed challenges in implementing social justice in mathematics classes, they seemed not applying the differences as an opportunity to create a variety of tasks and activities to teach and learn mathematics in a creative and constructive way. Different interests of students could be a natural phenomenon and should not be problem, rather an opportunity to deal with a variety of interests, needs, and aspirations of students. The most dominant view seems to be students' general loss of interest in mathematics. Nonetheless, the major challenge seems to be helping and motivating them in learning mathematics.

The challenges as perceived by the teachers (respondents) in relation to students' interests in mathematics seem to be aligned with Gutstein's (2007) idea of questioning and connecting pedagogy. The teachers who reported students not being interested in mathematics or having different interest in different domains of mathematics (e.g., arithmetic, algebra or geometry) did not use students' differential abilities as strength to promote interactive classroom sessions. Questioning pedagogy (asking meaningful questions) to engage students on mathematical tasks and activities related to their life and interests might motivate them to learn mathematics. The notion of interest plays a vital role in the academic and psychological discussion of learning and development. Being interested in learning is not only a valuable inspirational situation for persuasive learning, but it is also crucial in personality and selfconcept (Thorndike 1935). Many researchers use the notion of individual interest as a feature of a person. In other words, individuals are characterized by a more or less stable preference for a particular class of objects, topics, or learning tasks. Typically, individual interest is used as a predictor of academic performance. However, there is also research about advanced changes in interest such as gender-specific shifts in interest for various topics across years in school (Renninger 1998) and about the effects of people's situation-specific states of interest. These are typically referred to as realistic individual interests, and it may provide a basis of an emergent individual interest (Hidi and Anderson 1992; Hidi and Berndorff 1998). Thus, students have various interests in different subject areas. They also have various future goals that are difficult for the teachers to support in their consistent effort to those goals, which can be a cause of inequity in the classroom. 


\section{Non-participatory teaching}

It seems that traditional teaching techniques are also challenges for promoting social justice in mathematics classrooms. Chandra uses a board marker for teaching mathematics in the classroom and lectures most often.

Chandra revealed, "Due to a large number of students, it is not possible for me to make all students participate in different tasks" (Interview, August 28, 2016). He emphasizes more teacher-centered techniques in teaching mathematics. Saurya said, "The teachers' habits of traditional teaching in the classroom are challenges of social justice. So, the teachers need to be more active and encourage all students to participate in classroom activities" (Interview, August 27, 2016). Tara also expressed, "I use lecture methods with the help of marker and whiteboard. This sort of conventional teaching does not give the opportunity for students to participate in different tasks" (Interview, August 29, 2016).

Some of the important concepts from the participant narrative are large class size and teacher-centered teaching. It seems, from the participants' views, that there is a severe lack of responsibility of the teachers, schools, and education administration to reduce the class size. The large class seems to be a problem because teachers cannot focus on each students' learning and their participation in the classroom activities. The participants claimed that they could not implement the social justice approach to teaching mathematics because the class size outnumbered the general (ideal) class size appropriate for effective classroom activities to promote equity, access, and critical thinking in the classroom. Although the participants seem to believe that they need to encourage students to participate in the class activities, they resort to using a lecture chalk-and-talk approach to teaching mathematics. It seems a counter-intuitive view of these participants. On one side, they expressed their opinions that they want to engage students in learning through active participation, but on the other side, they failed to do it due to the conventional method of lecturing in the class. These concepts demonstrate the pedagogical issues as the source of challenges in student-centered teaching for social justice.

Promoting student-centered, participatory, and questioning-based teaching-learning of mathematics as suggested by Freire (1970), Habermas (1971), and Gutstein (2006, 2007) are key pillars of socially just pedagogy. However, the participants' reflections on their own teaching demonstrated a severe lack of conditions for social justice in mathematics teaching-learning in Nepal, posing a systemic challenge to bring transformation in schools and classrooms. When teachers use a participatory teaching approach, students are motivated to learn mathematics. They are close to their teachers. They learn mathematics more. But, teachers cannot quickly adopt a participatory approach because of classroom problems (Moscardini 2014). Conventional forms of mathematics instruction tend to focus on finding the right answer and memorizing facts and procedures, but often leave students unengaged and unprepared for difficult and innovative problem-solving (National Research Council [NRC] 2000). According to Ogunkunle (2007), mathematics instruction has taken a belief of talk and chalk. The application of the talk and chalk method has become problematic because it does not demonstrate the link between learning 
mathematics in the classroom and their applicability to real-life situations. Hence, it denies meaningful learning (Ogunkunle and George 2015; Sidhu 2006). It has been realized that the teacher-centered technique is one of the challenges of social justice in the mathematics classroom.

It seems that non-participatory teaching is a challenge for promoting social justice in the classroom. If teachers are active and students are passive then they just listen to the teacher's voice in one-way flow of communication. Teachers apply lecture methods for teaching mathematics. They have a dominant role in teaching but do not use child-friendly methods in the classroom. The conventional forms of mathematics instruction tend to focus on finding the right answers and memorizing facts and procedures but often leave students unengaged and unprepared for challenging and innovative problem-solving activities (NRC 2000).

\section{Insufficient skills in technology}

It is perceived that teachers need skills to use technology for teaching purposes. However, the lack of such skills is another challenge in mathematics teaching. Developing good skills in technology use may not be easy for all teachers.

Chandra shared, "I am not confident in using new technology in mathematics teaching. The course also should be reformed in such a way that it becomes technology-friendly so that students can enjoy applying technology while learning" (Interview, June 16, 2016). So, he needs a training to use technology. An insufficient skill in using technology is also a challenge for promoting social justice in the classroom. It can be seen that modern technology has been developing day by day. Teachers need to update their skills and be able to use new technology in the classroom. However, Saurya also said, "There is insufficient skillful human resources to help teachers to use technology. Teachers are not able to use technology for mathematics teaching. So, they are not mentally prepared to use technology" (Interview, August $27,2016)$. Tara pointed out that there is also a weakness of school administration in using technology as there is an insufficient visionary administrator. Tara expressed, "Teachers, in some schools, are not allowed to use mobile in the classroom. There is inadequate internet access in class. Therefore, teachers do not use the internet in their classrooms" (Interview, August 29, 2016).

Some of the major concepts in the above narrative are lack of confidence in using technology, lack of technical support for using technology, teachers' lack of readiness to use technology, weakness of school administration, ban on using cell phones in schools by students, and no or poor internet connection in the school and classrooms. When teachers are not confident in using the technological tools in mathematics classes, who should be blamed? Or, none to be blamed? Don't teachers have their responsibilities to learn and be updated about new technologies for teaching and learning mathematics? Technological tools, in most cases, are self-explanatory with a guidance and support that comes with the system. However, the teachers' need of training to the new technology is an obvious demand despite their ability to learn most technological tools (applications, videos, and tools) by their own. As per the participants' views, teachers are not mentally ready to use different technological 
tools in mathematics classes. They seem to shift the responsibility to the school administration and their vision. However, it is not clear to what extent the teachers are ready to accept their role and responsibility to learn about new technological tools and seek support from available resources from schools and government institutions. It also raises a question: to what extent teachers are aware of new technological tools in providing better equity, access, and opportunities to students to learn mathematics within and out of the classroom? It seems that getting access to technology in the classroom fosters social justice in the classroom context. Thus, the use of digital technology is necessary for mathematics teaching. This situation is problematic in many classroom contexts in Nepal, as there are insufficient skilled human resources. Many students may be interested in learning mathematics using technology. However, it is difficult to fulfill their interests to use technology for mathematics learning in many schools in Nepal because many teachers do not have the skills to use technology in the classroom although the situation has been different at present due to COVID-19 and teachers are using ICT for teaching mathematics during lockdown and school closures for face-to-face classes (Radhakrishnan-Nair 2020).

The use of technology and technological tools has been a norm in modern society, and it has impacted schools and classroom practices as well. However, this norm has not yet been fully realized in the context of Nepal. The above-mentioned challenges in terms of lack of skills to use technology reflect Freire's (1970) banking pedagogy in practice that hinders the systemic transformation in schools and classrooms. When teachers do not have technological skills to integrate mathematics with creativity and critical thinking with technology-mathematics interface, then classroom practices revert back to banking pedagogy severely crippling the notion of social justice with equity, equality, and access that technology might offer to the students' learning of mathematics. We can view the challenges with technology in mathematics teaching and learning as a technological obstacle in social justice.

The technological obstacles are related to two different conditions: material and non-material (Bingimlas 2009). The material conditions may probably refer to an inadequate number of computers or copies of the software in school, and non-materials obstacles include teachers' inadequate ICT knowledge and skills and the difficulty of integrating ICT in instruction. The BECTA (2004) concluded that many instructors do not think to be well skilled in using ICT. According to Carlson and Firpo (2001), "Instructors require powerful tools, techniques, and assistance that can support them in developing computer-based projects and activities specially designed to raise the level of teaching in required subjects and to improve student learning" (p.109). National Council of Teachers of Mathematics (NCTM 2000) stated that technology is necessary for teaching and learning mathematics as it affects the way mathematics is taught and learned. The way mathematics is taught determines the desired success of students. Highly efficient use of technology as a tool can assist in learning achievements (Suh 2010). Judson (2006) viewed that instructors play a vital role in technology use in the classroom. Instructors' self-efficacy and school situation can influence technology use in schools (Judson 2006). The participants viewed that many teachers are not confident enough and have poor interest in using new technology in the classroom. Additionally, there are not sufficient skilled human resources in the public high schools in Kathmandu. 
There are not sufficient materials in the classroom. There are only a limited number of textbooks, practice books, markers, dusters, copies, and pencils. There is a shortage of overhead projectors, computers, and laptops in many public schools in Nepal. Most teachers are not serious about the construction and collection of materials (local or readymade). There is insufficient mathematics lab in any school, which is necessary for teachers and students to verify theorems, facts, and construction of geometric figures. It is also necessary for project works. However, establishing a mathematics lab in school costs a lot. Going through the research question-How do mathematics teachers cope with the challenges of social justice in the mathematics classroom?-it was found inadequate technology as another challenge for promoting social justice in mathematics classrooms. Most classrooms do not have sufficient technology for teaching mathematics. Teachers' knowledge of content (CK), technological knowledge (TK), and pedagogical knowledge (PK) integrated together by Mishra and Kohler (2006) to construct a new framework called technological and pedagogical content knowledge (TPACK). However, this framework has not been fully realized in teacher training and development in Nepal. The lack of awareness and low competency to design lessons with TPACK and access to technological tools may pose challenges to socially just pedagogy in mathematics classroom (Bajracharya 2019). There are two types of such challenges: extrinsic (access, time, support, resources, and training) and intrinsic (attitudes, beliefs, practices, and resistance). Nonetheless, BECTA (2004) grouped the barriers based on whether they relate to an individual (teacher-level challenges) such as lack of time, lack of confidence, and resistance to change or institution level (school-level barriers), such as insufficient practical training to solve technical problems and inadequate access to resources.

\section{Cultural differences}

A culture includes ethnicity, language, geographic origin, and day-to-day practices. It is challenging to change traditional instructional techniques and adopt multicultural methods for teaching and learning mathematics.

Chandra said, "Cultural difference is one of the challenges for maintaining social justice in the classroom. Because of cultural diversity, they have different feelings. The effect of the difference among the students due to culture is reflected in their behaviors" (Interview, August 28, 2016). Saurya opined, "Students dominate each other on the basis of religion and cultural differences. Even teachers behave differently with their students based on their cultural background. For instance, some teachers appreciate one group of students consciously or subconsciously dominate another group of students and others. That influences the teaching and learning of mathematics" (Interview, August 27, 2016). Tara also accepts the existence of cultural differences in the classrooms. Tara further stated, "Students from different ethnic groups behave differently with their friends in their classroom. Some children from minority groups hesitate to take part in different activities as they feel dominated by a certain group" (Interview, August 29, 2016). 
Some of the critical concepts in the above narrative are as follows: the dominance of certain groups, differential behavioral patterns, and student hesitation to participate. Is cultural difference a challenge or an opportunity? For a good teacher, the cultural difference among the students should be an opportunity to introduce different ideas related to the cultures in mathematics classroom practices. Of course, it may require extra precaution and preparation on the part of the teachers to prepare the mathematical tasks and related materials to engage students in meaningful learning of mathematics in a cultural and social context. When students of one cultural group dominate other students, then who is responsible for students' attitudes? Aren't teachers accountable for managing the classroom environment in a respectful manner by acknowledging the differences and valuing the different ideas from different students? The research participants' opinions demonstrate that the mathematics teachers are not aware of social justice, equity, and access to high-quality pedagogical activities that promote respect, human values, and ethics. These elements pose a challenge to balance the role and activities of the students in mathematics classroom to promote equal access and opportunity to learn mathematics. The participants argued that there are various cultural differences among the students as there are different religious, ethnic, and cultural groups in society. Students of one religion slightly and ethnicity dominate students of other cultures and religions in the classroom. Some teachers are also biased in terms of religion and culture. These dominances may affect any classroom in general and mathematics classes in particular due to a lack of interaction and mathematically caring relations (Hackenberg 2010). Diversity became a source of ethnic and linguistic disparity in educational outcomes instead of a gain (Mathema and Bista 2006).

The participants' perceived cultural differences in the classroom should not be a threat to social justice in mathematics learning. Rather, it could be a strength. However, the participants viewed it as a challenge to promote social justice. That means these teachers (participants) were not aware of multiculturalism as an integral aspect of modern education. Multiculturalism may provide teachers and students an opportunity to develop a culturally sensitive and socially responsible pedagogical practice in mathematics classroom, challenging the notion of banking pedagogy Freire's (1970) and embracing Habermas's emancipatory interests of mathematics teaching and learning. In this context, cultural psychology has demonstrated various cultures that people make attributions for social behaviors (Ishii 2007). The school environment and the role of teachers are important; teachers need to be aware of the diversity that exists in the classroom and how socio-cultural factors affect the academic performance of students (Haghi et al. 2013). Teachers' perceptions and attitudes towards cultural diversity are crucial for student motivation towards learning. Researchers have historically interpreted culture as either the norms and values or the competencies and practices that distinguish one racial group from another (Lewis et al. 2008). Therefore, teachers have a challenge to include students' mathematical funds of knowledge in their classrooms (González 2001), specifically to design lessons and mathematical tasks pertaining to their own culture (Aguirre et al. 2019). Culturally relevant pedagogy acknowledges students' funds of knowledge and includes it during mathematics instruction (Gallivan, 2017). White et al. (2016) also believe that teachers need to apply culturally responsive instructional strategies, 
which apply cultural knowledge and experiences to evolve each student's mathematics knowledge. The diversity of students seems to be a major challenge of social justice in mathematics classrooms. Students are from various backgrounds such as cultural, economic, social, geographical, academic, and non-academic. Students have a distinct culture, language, and history. Therefore, it is difficult to teach them, creating an environment of equity, respect, and value of their social and cultural identity due to a lack of support from the school and the government.

\section{Implications}

The result of this study has two significant implications-policy implication and pedagogical implication. The policy implication focuses intervention to reform mathematics curricula, textbooks, and models of teacher education. The pedagogical implication focuses on the practical application of socially just teaching and learning in the mathematics classroom.

\section{Policy implication}

The outcome of the study in terms of the eight themes and related interpretation highlights the benefits of social justice in the mathematics classrooms and how teachers face challenges for promoting social justice impacts teaching, learning, and student performance. Mathematics teachers, teacher educators, education experts, curriculum planners, policymakers, and all stakeholders should understand the existing situation and practices of social justice in the mathematics classroom. It gives insights for transforming the curriculum and for promoting social justice in the classroom. The themes, diverse students, working children, and students' absenteeism, are not only related to classroom dynamics, but also, they are political in nature. Therefore, they have more considerable policy implications for transforming education in general and mathematics teaching-learning in particular by challenging the status quo and embracing critical thinking (Freire 1970). In a classroom context, it is possible to maintain and sustain social justice only when each student has equal access to resources (e.g., books, accessories, technology, and time). Another key element of social justice, as perceived by the teachers, is equity. Teachers' perception of equity shows some misconception of this construct, and hence it cannot be well addressed by only the efforts of schools and teachers (Panthi et al. 2018a). The perception of social justice is not limited to the classroom, but its impact is high on the social, political, and cultural milieu. Hence, these issues call for broader policy reform in mathematics education.

\section{Pedagogical implication}

The study has outlined the processes that enable the transformation of classroom practices to other situations. It has also highlighted how high school mathematics 
teachers perceive social justice and the challenges associated with mathematics classrooms. All the themes that emerged in this study have pedagogical implications. However, two of them are diverse students, and disengaging pedagogy has even a greater significance in terms of teaching and learning mathematics by creating socially just classroom practices. Equality, equity, and fairness have a broader implication. Hence, teachers have less control over them because these constructs are broader in scope and stronger in influence socially, politically, and culturally. The themes, the different interests of students, a large number of students, non-participatory teaching, insufficient skills in using technology, are related to pedagogy that is in the scope of teachers' roles and responsibilities to improve socially just classroom practices. These thematic findings are also associated to technical, practical, and emancipatory knowledge constitutive interests (Habermas 1971) in schools and social, cultural, and historical contexts of Nepal. In this context, a teacher should use equitable pedagogy in which students develop practical and emancipatory interests in mathematics beyond the routine of problem-solving guided by technical interest. Teachers should make them happy and enjoy the classroom. These actions are first in the hands of teachers to enhance learning to perceive social, political, and economic contradictions, and to act against the oppressive elements of reality through the pedagogy of questioning and dialectical relationships among students and teachers in mathematics classrooms (Gutstein 2007).

\section{Limitations and conclusion}

This study has some limitations in the method of data collection, and hence it has a limitation in the scope of generalization. There was a limitation in the method of data collection through interviews with three teachers. Each participant teacher was interviewed twice. However, these limited numbers of interviews had a limited amount of data for the saturation of themes. Hence, the findings with the eight themes that emerged from the data cannot be generalized for other cases. The sources of data have been limited to teacher interviews and class observations. Interviews with students and parents would provide a better interpretation of data triangulation. Besides the limited number of cases, there was a limitation of the analytical approach with the construction of thematic structures from the qualitative interview data. These thematic structures were based on the central ideas and peripheral concepts generated through concept mapping in a matrix form. The central and peripheral ideas and concepts are very subjective in nature, and hence their formation and interpretation are based on the researcher's subjectivity and worldview.

Social justice issues in classrooms can be perceived as a by-product of social, cultural, political, and historical contexts of schools and places where these institutions exist. This study outlined several challenges for promoting social justice in mathematics classrooms such as diverse students, working-class children, disengaging curriculum, inadequate prior knowledge, students' different interest, non-participatory teaching, and insufficient skills in using technology. Therefore, the study's findings conclude that teachers, school leaders, teacher educators, institutions, and the government authorities responsible for teacher education and development should 
consider these challenges for social justice in mathematics classroom as a threat to transform education and work collaboratively at policy and practice levels to tackle with these challenging factors. The National Curriculum Framework of Nepal 2020 has emphasized child rights, gender equality, equity, and free basic and secondary education with access and improvement in education of all levels (Curriculum Development Center 2019). In this context, the findings of the current study indicated that teachers and schools should be provided with adequate moral, physical, and psychological support to combat the challenges in promoting social justice in schools in general and mathematics classrooms in particular.

Funding There was no funding from any institution to conduct this study.

Data availability The data for this study are not available due to the privacy of participants.

\section{Declarations}

Conflict of interest The authors declare no conflict of interest in the publication of this manuscript.

\section{References}

Aguirre J, Herbel-Eisenmann B, Celedon-Pattichis S, Civil M, Wilkerson T, Stephan M, PapeClements. S (2017) Equity within mathematics education research as a political act: moving from choice to intentional collective professional responsibility. J Res Math Educ 48(2):124-147

Aguirre JM, Anhalt CO, Cortez R, Turner EE, Simic-Muller K (2019) Engaging teachers in the powerful combination of mathematical modeling and social justice: the flint water task. Mathem Teach Educ $7(2): 7-26$

Bajracharya JR (2019) TPACK-integrated worked examples for technology integration. J Train Dev 4:4663. https://doi.org/10.3126/jtd.v4i0.26837

Bartell TG (2013) Learning to teach mathematics for social justice: Negotiating social justice and mathematical goals. J Res Math Educ 44(1):129-163

Belbase S (2006) My journey of learning and teaching mathematics from traditionalism to constructivism: A portrayal of pedagogical metamorphosis (Unpublished M Phil dissertation). Kathmandu University, Dhulikhel, Nepal

Berger R (2015) Now I see it, now I don't: Researcher's position and reflexivity in qualitative research. Qual Res 15:219-234. https://doi.org/10.1177/1468794112468475

Bhattarai NK (2017) What factors affect school attendance?: Quantitative and qualitative study of evidences from Nepal. Doctoral dissertation, Colorado State University, Fort Collins, CO, USA

Bialik M, Kabbach A (2014) Mathematics for 21st century: What should students learn? Center for Curriculum Design, Boston, MA

Bingimlas KA (2009) Barriers to the successful integration of ICT in teaching and learning environments: A review of literature. Eur J Mathem Sci Technol 5(3):235-245

Bold C (2012) Using narrative in research. Sage, London. https://doi.org/10.4135/9781446288160

Bolyan M, Woolsey I (2015) Teacher education for social justice: mapping identity spaces. Teach Teach Educ 46(1):62-71. https://doi.org/10.1016/j.tate.2014.10.007

Bolyan M, Woolsey I (2016) Teacher education for social justice: mapping identity spaces. Teach Teach Educ 46(1):62-71

Bose E, Remillard J (2011) Looking for equity in policy recommendations for instructional quality. In: Atweh B, Graven M, Secada W, Valero P (eds) Mapping equity and quality in mathematics education. Springer, New York, NY, pp 177-190 
British Educational and Communications Technology Agency (BECTA) (2004) A review of the research literatures on barriers to the updates of ICT by teacher. https://dera.ioe.ac.uk/1603/1/becta_2004_ barrierstouptake_litrev.pdf. Accessed 12 March 2018.

Brown R (2009) Teaching for social justice: Exploring the development of student agency through participation in the literacy practices of a mathematics classroom. J Math Teach Educ 12(2009):171185. https://doi.org/10.1007/s10857-009-9110-07

Burton L (ed) (2003) Which way social justice in Mathematics education? Praeger, London

Cafezeiro I, Kubrusly R, Marques IC, Cafezeiro E (2017) Paulo Freire, mathematics, and policies that shape mathematics. J Indian Council Philosoph Res 34:227-246

Carlson S, Firpo J (2001) Integrating computers into teaching: Findings from a 3-year program in 20 developing countries. In: Vandervert LR, Shavinina LV, Cornell RA (eds) Cyber education: The future of distance learning. Mary Ann Liebert Inc, Larchmont, NY, pp 85-114

Chaves-Barboza E, Marin-Marin J-A, Sarmento-dos-Santos A-P, Trujillo-Torres J-M (2019) Student absenteeism in mathematics lessons: Social variables in the PGS of Namibe. Education Sciences 9(2):130. https://doi.org/10.3390/educsci9020130

Christians CG (2018) Ethics and politics in qualitative research. In: Denzin NK, Lincoln YS (eds) The SAGE handbook of qualitative research, 5th edn. SAGE, pp 142-171

Clandinin DJ, Connelly FM (2000) Narrative inquiry: experience and story in qualitative research. Jossey-Bass, San Francisco

Clarkson P, Presmeg N (2008) Critical issues in mathematics education: Major contribution of Alan Bishop. Springer, New York

Cochran-Smith M (2004) Walking the road: Race, diversity, and social justice in teacher education. Teachers College Press, New York, NY

Curriculum Development Center (CDC) (2007) National curriculum framework for school education in Nepal 2007. Ministry of Education, Nepal

Curriculum Development Center (CDC) (2019) National curriculum framework for school education 2019. Ministry of Education, Science and Technology, Nepal

Dahal N, Luitel BC, Pant BP (2019) Understanding the use of questioning by mathematics teachers: A revelation. Int J Innov Creat Change 5(1):118-146. https://ijicc.net/images/Vol_5_iss_1_2019/ Dahal_Nov_2019.pdf

Darling-Hammond L (1995) Inequality and access to knowledge. In: Banks JA (ed) Handbook of research on multicultural education. Macmillan, New York, pp 465-483

DeKalb J (1999) Student truancy. (Report No. EDO-EA-99-1). Washington, DC: Office of Educational Research and Improvement

Doerr H, Chandler-Olcott K (2005) Mathematics and literacy: An interdisciplinary perspective on teaching with reform-based curricula in urban middle schools. Paper presented at the annual meeting of the North American Chapter of the International Group for the Psychology of Mathematics Education, Roanoke, 20-23

Education Review Office (ERO) (2018) Annual report of Education Review Office for 2017-18. Sanothimi, Bhaktapur: Ministry of Education, Science, and Technology, Nepal

Ernest P, Sriraman B, Ernest N (eds) (2016) Critical mathematics education: Theory, praxis, and reality. Information Age Publishing Inc., Charlotte, NC

Esmonde I, Caswell B (2010) Teaching mathematics for social justice in multicultural, multilingual elementary classrooms. Can J Sci Mathem Technol Educat 10(3):244-254

Frambach JM, van der Vleuten CPM, Durning S (2013) AM last page: quality criteria in qualitative and quantitative research. Acad Med 88(4):552. https://doi.org/10.1097/ACM.0b013e31828abf7f

Freire P (1973) Education for critical consciousness. Seabury Press, New York

Freire P (1970) Pedagogy of oppressed (M.B. Ramos, Trans.), Seabury Press, New York

Gallivan HR (2017) Supporting prospective middle school teachers' learning to revise a high-level mathematics task to be culturally relevant. Mathem Teacher Educ 5(2):94-121

Garii B, Rule AC (2009) Integrating social justice with mathematics and science: an analysis of student teacher lessons. Teach Teach Educ 25(3):490-499

Gates P (2009) Foregrounding social justice in mathematics teacher education. J Mathem Teacher Educ $1-4$

Gautam GR (2016) Teacher training in Nepal: issues and challenges. Tribhuvan Unive J XXX(2):44-56. https://doi.org/10.3126/tuj.v30i2.25545 
Gebremichael AT (2014). Students' perception about the relevance of mathematics to other school subject. Proceedings of the frontiers in mathematics and science education research conference (1-3 May). Famagusta, North Cyprus

Giri RA (2010) Cultural anarchism: the consequences of privileging languages in Nepal. J Multil Multicult Dev 31(1):87-100. https://doi.org/10.1080/01434630903398103

González N, Andrade R, Civil M, Moll L (2001) Bridging funds of distributed knowledge: creating zones of practices in mathematics. J Educ Stud Placed Risk 6(1-2):115-132. https://doi.org/10.1207/ S15327671ESPR0601-2_7

Government of Nepal (GoN) (2015). he Constitution of Nepal 2015. Government of Nepal. https://www. mohp.gov.np/downloads/Constitution\%20of\%20Nepa1\%202072_full_english.pdf

Government of Nepal (GoN) (2018) The Act Relating to Compulsory and Free Education, 2018. Government of Nepal. http://www.lawcommission.gov.np/en/wp-content/uploads/2019/07/The-Act-Relat ing-to-Compulsory-and-Free-Education-2075-2018.pdf

Grant HA (2020) Book Review: Keeping mathematics education real and fair: connecting the disconnections. Constantinos Xenofontos (ed) (2019) Equity in mathematics education: addressing a changing world. Educ Stud Mathem 104:439-444

Greenstein S, Russo M (2019). Teaching for social justice through critical mathematical inquiry. Occasional Paper Series, 2019(41), Article 1. https://educate.bankstreet.edu/occasional-paperseries/ vol2019/iss41/1

Grundy S (1987). Three fundamental human interests. Curriculum: product or praxis? London. The Falmer Press

Gutiérrez R (2008) A gap-gazing fetish in mathematics education? Problematizing research on the achievement gap. J Res Math Educ 39(4):357-364

Gutiérrez R (2009) Embracing the inherent tensions in teaching mathematics from an equity stance. Democr Educ 18(3):9-16

Gutstein E (2006) Reading and writing the world with mathematics: toward pedagogy for social justice. Routledge, New York

Gutstein E, Peterson R (eds) (2006) Rethinking mathematics: teaching social justice by the numbers. Rethinking Mathematics Ltd., Milwaukee

Gutstein E, Peterson B (eds) (2005) Rethinking mathematics: Teaching social justice by the numbers. Rethinking Schools, Milwaukee

Gutstein E (2007). And that's just how it starts: Teaching mathematics and developing student agency. Teach Coll Rec109:420-448. http://www.tcrecord.org

Habermas J (1971) Knowledge and human interests. In: Shapiro J. J. (trans.). Boston: Beacon. [German, 1968]

Hackenberg A (2010) Mathematical caring relations: a challenging case. Math Educ Res J 22:57-83. https://doi.org/10.1007/BF03219778

Haghi SE, Rostamy-Malkhalifeh M, Behzadi MH, Shahvarani A (2013) The cultural diversity and its role in mathematical activities. Mathem Educ Trends Res 2013:1-9. https://doi.org/10.5899/2013/ metr-00028

Hamdan AK (2009) Reflexivity of discomfort in insider-outsider educational research. J Educ 44:377404. https://doi.org/10.7202/039946ar

Hidi S Berndorff D (1998) Situational interest and learning. In: Hoffmann L, Krapp A, Renninger KA, Baumert J (eds) Interest and learning. Proceedings of the see on conference on interest and gender, Institut fur die Padagogik der Naturwissenschaften, Kiel, Germany

Hidi S, Anderson V (1992) Situational interest and its impact on reading and expository writing. In: Renninger KA, Hidi S, Krapp A (eds) The role of interest in earning land development. Erlbaum, Hillsdale, NJ, pp 215-238

Hodge LL, Harris RG (2015) Voice, identity, and mathematics: narratives of working-class students. J Educ Issues 1(2):129-148. https://doi.org/10.5296/jev.v1i2.8314

International Labor Organization (ILO) (2020) Eliminating child labor in Nepal: Facts, figures, commitments and action. Dhobighat, Lalitpur Nepal: ILO Country Office in Nepal. https://www.ilo.org/ wcmsp5/groups/public/---asia/---ro-bangkok/---ilo-kathmandu/documents/projectdocumentation/ wcms_182777.pdf

Ishii K (2007) Do differences in general trust explain cultural differences in dispositionism? Jpn Psychol Res 49(4):282-287. https://doi.org/10.1111/j.14685884.2007.00354.x

Judson E (2006) How teachers integrate technology and their beliefs about learning: is there a connection? J Technol Teach Educ 14(3):581-597 
Kandel P (2018) After quantity, Nepal's education needs quality. Nepali Times. https://www.nepalitimes. com/banner/after-quantity-nepals-education-needs-quality/

Kelly DM, Brandes GM (2008) Equitable classroom assessment: promoting self-development and selfdetermination. Interchange 39(1):49-76. https://doi.org/10.1007/s10780-008-9041-8

Kentucky Department of Education. (2007). Characteristics of high-quality mathematics teaching and learning in Kentucky schools. https://education.ky.gov/curriculum/standards/teachtools/Docum ents/Mathbibliographyandresearch.pdf

Lamichhane BR (2018) Assessment practices in mathematics: local to global contexts. Saptagandaki J IX. https://doi.org/10.3126/sj.v9i0.20876

Leonard J, Moore CM (2014) Learning to enact social justice pedagogy in mathematics classrooms. Action Teach Educ 36(1):76-95. https://doi.org/10.1080/01626620.2013.861371

Lewis A, O'Connor C, Mueller J (2008) Discrimination, culture, or capital? Handbook of social justice in education, London: Routledge. https://doi.org/10.4324/9780203887745.ch17

Lim CS, Pateman NA (2013) The politics of equity and access in teaching and learning mathematics. In: Ken MA, Clements, Bishop AJ, Keitel C, Kilpatrick J, Leung FKS (eds) Third international handbook of mathematics education, Springer, New York, (pp 243-263)

Lincoln YS, Guba E (1985) Naturalistic inquiry. Sage, Beverly Hills, CA

Lindgren R, McDaniel R (2012) Transforming online learning through narrative and students' agency. Educ Technol Soc 15(4):344-355

Luitel BC (2013) Mathematics as an im/pure knowledge system: symbiosis (w)holism and synergy in mathematics education. Int J Sci Math Educ 10(6):65-87. https://doi.org/10.1007/s10763-012-9366

Luitel BC (2009) Culture, worldview and transformative philosophy of mathematics education in Nepal: A cultural philosophical inquiry. Doctoral dissertation, Curtin University. https://espace.curtin.edu. au/handle/20.500.11937/682

Martin DB (2003) Hidden assumptions and unaddressed questions in Mathematics for All rhetoric. Math Educ 13(2):7-21

Mathema KB, Bista MB (2006) Study on student performance in SLC: Main report. Ministry of Education and Sports, Nepal, Kathmandu

Michelsen C, Sriraman B (2009) Does interdisciplinary instruction raise students' interest in mathematics and the subjects of natural sciences? ZDM 41:231-244

Mishra P, Koehler MJ (2006) Technological pedagogical content knowledge: a framework for teacher knowledge. Teach Coll Rec 108(6):1017-1054

Morrison KRB (1995) Habermas and the school curriculum: an evaluation and case study. Doctoral dissertation, Durham University

Morse J (2018) Reframing rigor in qualitative inquiry. In: Denzin NK, Lincoln YS (eds) The SAGE handbook of qualitative research, 5th edn. SAGE, pp 1373-1409

Moscardini L (2014) Developing equitable elementary mathematics classroom through teacher learning about children's mathematical thinking: cognitively guided instruction as an inclusive pedagogy. Teach Teach Educ 43:69-79

Motlhaka HA (2017) Paulo Freire's critical pedagogy in the classroom: promotion of critical thinking in South African English first additional language (FAL) students. Int J Educ Sci 13(1):65-71. https:// doi.org/10.1080/09751122.2016.11890441

Munter C (2014) Developing visions of high-quality mathematics instruction. J Res Math Educ 45(5):584-635

National Council of Teachers of Mathematics (NCTM) (1991) Professional standards for teaching mathematics, NCTM, Reston, VA

National Council of Teachers of Mathematics (NCTM) (2000) Principles and standards for school mathematics, NCTM, Reston, VA

National Council of Teachers of Mathematics (NCTM) (2014) Access and equity in mathematics education: A position of the national council of teachers of mathematics. Reston, VA: NCTM. https:// www.nctm.org/uploadedFiles/Standards_and_Positions/Position_Statements/Access_and_Equity. pdf

National Research Council (2000) How people learn: brain, mind, experience, and school. In: Bransford JD, Brown A, Cocking R (eds) National Academies Press, Washington, DC

Ogunkunle RA (2007) Constructivism: an instructional strategy for sustaining student's self-concept in secondary school mathematics. J Sci Teach Assoc Nigeria 41:30-50

Ogunkunle RA, George NR (2015) Integrating ethnomathematics into secondary school mathematics curriculum for effective artisan creative skill development. Eur Sci J 11(3):386-397 
OXFAM \& HAMI (2019) Fighting inequity in Nepal: the road to prosperity. OXFAM International and HAMI. https://oxfamilibrary.openrepository.com/bitstream/handle/10546/620607/bp-fightinginequality-nepal-110119-en.pdf

Padilla A, Tan P (2019) Toward inclusive mathematics education: a metatheoretical reflection about countering ableism in mathematics standards and curriculum. Int J Qual Stud Educ 32(3):299-322. https://doi.org/10.1080/09518398.2019.1576941

Pangeni KP (2014) Factors determining educational quality: Student mathematics achievement in Nepal. Int J Educ Dev 34:30-41. https://doi.org/10.1016/j.ijedudev.2013.03.001

Pant BP (2015) Pondering on my beliefs and practices on mathematics, pedagogy, curriculum and assessment (Unpublished MPhil in Mathematics Education dissertation). Kathmandu University, Dhulikhel, Nepal

Panthi RK (2017). Social justice in mathematics classroom: an interpretive inquiry. M. Phil. Dissertation, Nepal, Kathmandu University

Panthi RK (2019) Factor responsible for socially just pedagogy in mathematics education. In Subramanian J (ed), Mathematics education and society. Proceedings of the Tenth International Mathematics Education and Society Conference, 28th January-2nd February, 2019, Sri Satya Sai Designing Studio Pvt Ltd, Hyderabad, India

Panthi RK, Belbase S (2017) Teaching and learning issues in mathematics in the context of Nepal. Eur J Educ Soc Sci 2(1):1-27

Panthi RK, Luitel BC, Belbase S (2018a) Teachers' perception of social justice in mathematics classrooms. J Res Mathem Educ (REDIMAT) 7(1): 7-37. https://doi.org/10.17583/redimat.2018.2707

Panthi RK, Luitel BC, Belbase S (2018b) Strategies for promoting social justice in mathematics classroom. Int J Emerg Mathem Educ 2(1):17-38. https://doi.org/10.12928/ijeme.v2i1.6809

Plunkett D (2013) Dworkin's interpretivism and the pragmatics of legal disputes. Leg Theory 19:242-281

Quaye J (2020) Attitudes towards mathematics and mathematical achievement in secondary schools in England: exploring the role of social class, gender and ethnicity. Res Mathem Educ 17(1):59-60. https://doi.org/10.1080/14794802.2014.971340

Radhakrishnan-Nair K, Aedo C, Aryal MP, Sherpa M, Sharma U (2020) Nepal steps up in remote learning during COVID-19. World Bank. https://blogs.worldbank.org/endpovertyinsouthasia/nepalsteps-remote-learning-during-covid-19

Read BL (2018) Serial interviews: when and why to talk to someone more than once. Int J Qual Methods 17:1-10. https://doi.org/10.1177/1609406918783452

Renninger KA (1998) The role of individual interest(s) and gender in learning: an overview of research on preschool and elementary school-aged children/students. In: Hoffmann L, Krapp A, Renninger KA, Baumert J (eds) Interest and learning. Proceedings of the Seeon-Conference on interest and gender, Institut fur die Padagogik der Naturwissenschaften, Kiel, Germany, (pp. 165-174)

Rijal RR, Paudel NP, Gautam S, Bista SK, Khatiwada TR, Chongbang KB (2018) A study on factors of student learning achievements and dynamics for better learning conditions: A case study focused to grade five in some selected schools. The Department of Education, Ministry of Education, Nepal. https://www.doe.gov.np/assets/uploads/files/632761d93738aa7abd6159bc9f642c33.pdf

Sidhu KS (2006) The teaching of mathematics. Sterling Publishers Private Limited, New Delhi

Skovsmose O (2011) An invitation to critical mathematics education. Sense Publishers, Rotterdam

Skovsmose O, Penteado MG (2011) Ghettoes in the classroom and the construction of possibilities. In: Atweh B, Graven M, Secada W, Valero P (eds) Mapping equity and quality in mathematics education. Springer, New York, NY, pp 77-90

Stinson DW, Bidwell CR, Powell GC (2012) Critical pedagogy and teaching mathematics for social justice. Int J Crit Pedag 4(1):76-94

Stoehr KJ (2019) Prospective teachers' reflections across the community mathematics exploration module. In: Bartell TG, Drake C, McDuffie AR, Aguirre JM, Turner EE, Foote MQ (eds) Transforming mathematics teacher education: An equity-based approach. Springer, Cham, Switzerland, pp 77-91

Suh JM (2010) Leveraging cognitive technology tools to expand opportunities for critical thinking on data analysis and probability in elementary classrooms. J Comput Math Sci Teach 29(3):289-302

Tanko MG (2014) Challenges associated with teaching mathematics for social justice: Middle Eastern perspectives. Learning and teaching in higher education: Gulf perspectives 11(1). http://lthe.zu.ac. ae.

Taylor,PC, Luitel BC (2005) Overcoming culturally dislocated curricula in a transitional society: an autoethnographic journey towards pragmatic wisdom. Paper presented at the annual meeting of 
the American Educational Research Association (AERA), SIG: Self-Study of Teacher Education Practices Montreal.

Thorndike EL (1935) Adult interests. Macmillan, New York

United Nations International Children's Emergency Fund (UNICEF) (1990) United Nations Convention on Rights of the Child. UNICEF UK. https://tinyurl.com/epmppr6y

Verhoeven M (2011) Multiple embedded inequalities and cultural diversity in educational systems: a theoretical and empirical exploration. Eur Educ Res J 10(2):189-203. https://doi.org/10.2304/eerj. 2011.10.2.189

Vomvoridi-Ivanovic E, McLeman L (2015) Mathematics teacher educators focusing on equity: potential challenges and resolutions. Teach Educ Q 42(4):83-100

Wagle SK (2016) From hopelessness to hope at academics: a self-reflective inquiry on the conditioning of learning emotions (Unpublished M Phil dissertation). Kathmandu University, Dhulikhel, Nepal

Wagle SK, Luitel BC, Krogh E (2019) Irrelevance of basic school education in Nepal: an anti-colonial critique on problems and prospects. Dhaulagiri J Sociol Anthropol 13:31-39. https://doi.org/10. 3126/dsaj.v13i0.24032

Wagley MP, Sharma TN, Koirala BN, Ramos SY, Taylor PC, Luitel BC, Belbase S, Pokhrel TR, Poudel A, Neupane GK, Poudel KP, Adhikary NP, Dahal RC, Bhandari U (2008) Developing culturally contextualized mathematics resource materials: capturing local practices of Tamang and Gopali communities. UNESCO. https://un.info.np/Net/NeoDocs/View/1398

White DY, DuCloux KK, Carreras-Jisino AM, Gonzalez DA, Keels K (2016) Preparing preservice teachers for diverse mathematics classrooms through a cultural awareness unit. Mathem Teach Educ 4(2):164-187

World Bank. (2021a). Population, total - Nepal. https://data.worldbank.org/indicator/SP.POP.TOTL?locat ions $=\mathrm{NP}$

World Bank. (2021b). GNI per capita, Atlas method (current US\$) - Nepal. https://data.worldbank.org/ indicator/NY.GNP.PCAP.CD?end $=2019 \&$ locations $=$ NP\&start $=1962 \& v i e w=$ chart

Yasoda R (2009) Problems in teaching and learning mathematics. Discovery Publishing House, New Delhi

Yeh C, Ellis M, Mahmood D (2020) From the margin to the center: a framework for rehumanizing mathematics education for students with dis/abilities. J Mathem Behav. https://doi.org/10.1016/j.jmathb. 2020.100758 